\title{
Risk Analysis of Brown Rot Blossom Blight of Prune Caused by Monilinia fructicola
}

\author{
Y. Luo, D. P. Morgan, and T. J. Michailides
}

Department of Plant Pathology, University of California-Davis, Kearney Agricultural Center, Parlier 93648. Accepted for publication 26 April 2001.

\begin{abstract}
Luo, Y., Morgan, D. P., and Michailides, T. J. 2001. Risk analysis of brown rot blossom blight of prune caused by Monilinia fructicola. Phytopathology 91:759-768.

Experiments under controlled environmental conditions were conducted during bloom of prune (Prunus domestica, L.) in 1999 and 2000 to assess the effects of inoculum concentration (IC), wetness duration (WD), temperature, and bloom stages on development of brown rot blossom blight of prunes. Branches from trees of a prune orchard were inoculated with Monilinia fructicola at different bloom stages and incubated at different temperatures with different periods of WD. The proportion of blighted blossoms (PBB) for each inoculated branch was determined. Bloom stage, IC, temperature, and WD significantly affected blossom blight of prunes. PBB at popcorn and full bloom stages was significantly greater than PBB at later bloom stages $(P \leq 0.05)$. The optimal temperatures for
\end{abstract}

ABSTRACT

Monilinia fructicola (G. Wint.) Honey, is the main causal pathogen of brown rot on stone fruits (Prunus spp.) $(1,3,13,23)$. Ascospores and conidia produced from mummies infected by $M$. fructicola disperse in the air (11) and cause primary infections in the spring $(3,13,20)$. Primary infections can also function as a source of latent infection of fruit $(6,9,10,24)$. Blossom blight may cause severe yield losses on stone fruit by reducing the number of flowers. Infected blossoms with sporulation may serve as sources of conidial inoculum for infection of fruit $(13,20)$. Spraying fungicides at early bloom is a major strategy to control this disease of prunes and other stone fruits (26).

Blooming season of stone fruits in California may last for approximately 2 months, starting in mid-February for peach and ending in mid-April for prune. Although pandemics of brown rot blossom blight occurs infrequently in California, disease of various severity levels often occurs in different host species and at different locations. Inoculum potential and weather conditions in orchards during bloom can significantly influence disease development (16). In orchards with a history of severe brown rot and high inoculum potential associated with disease favorable microclimatic conditions, chemical control at green tip stage has been routinely applied. However, most of the orchards have low levels of inoculum potential and are subjected to changing weather conditions during bloom. Growers have difficulty making decisions regarding if or when chemical control is necessary. Precise estimation of the risk for blossom blight development can effectively reduce cost of disease control.

Analysis of main factors that affect development of brown rot blossom blight is critical in risk assessment procedures. Tem-

Corresponding authors: Y. Luo and T. J. Michailides

E-mail addresses: yLuo@uckac.edu and themis@uckac.edu, respectively

Publication no. P-2001-0529-01R

(C) 2001 The American Phytopathological Society blossom blight development were 22 to $26^{\circ} \mathrm{C}$, and Gaussian functions were used to describe the relationship between $\mathrm{PBB}$ and temperature. PBB linearly increased with increased IC. Linear regressions of PBB on WD were obtained for each combination of bloom stage, IC, and temperature. The parameters of these regressions were used in a computer program to produce the possible maximum PBB with $90 \%$ probability $\left(\mathrm{PBB}_{90}\right)$ using stochastic simulations. Early bloom stages with a higher IC at temperatures from 20 to $25^{\circ} \mathrm{C}$ were associated with more severe blossom blight than late stages with a lower IC at nonoptimal temperatures. Blossom blight did not occur at $<10$ or $>30^{\circ} \mathrm{C}$ and less than 4-h WD. However, longer than 4-h WD linearly increased incidence of blossom blight. A risk assessment table of blossom blight was produced for different environmental conditions to guide the control of prune brown rot.

Additional keywords: quiescent infection, stone fruits. perature and wetness duration (WD) are important environmental factors affecting the development of blossom blight. Wilcox (25) studied brown rot blossom blight of sour cherry and demonstrated that incidence of blossom blight increased when inoculated plants were incubated at $8,12,16$, and $20^{\circ} \mathrm{C}$ from 5 to $10 \mathrm{~h}$ of wetness, and reached a level of 85 to $90 \%$ after $24 \mathrm{~h}$ of wetness. This study (25) also showed that blossom blight incidence was influenced by inoculum concentration (IC). Tamm et al. (21) studied the influence of temperature, WD, and phenological stage on blossom blight of sweet cherry caused by M. laxa and established a nonlinear model to describe the incidence of infection as a function of temperature and WD. Koball et al. (12) determined that severity of blossom blight of sour cherry increased with increased humidity during the incubation period. Infection of fruit was also affected by environment. Optimal temperature range for infection of fruit by $M$. fructicola was between 20 and $25^{\circ} \mathrm{C}(2,4,18,21)$. Longer periods of wetness could bring about more severe infection of fruit than shorter periods of wetness $(2,21)$. Severity of infection of fruit increased with increased IC $(5,9,13,16,17,25)$.

Commercial recommendations for fungicide spay to control brown rot blossom blight is at the green tip stage. However, the importance of chemical control for blossom blight at different bloom stages may be different. A better understanding of risk for blossom blight development, after considering combinations of bloom stage, inoculum potentials, and environmental conditions, could help in establishing a warning system for efficient disease control.

Risk of plant disease can be defined as the probability of occurrence of a certain intensity of incidence or severity. For example, a possible risk of brown rot blossom blight can be estimated as $10 \%$ incidence with $85 \%$ probability. Risk of plant disease can also be determined as the maximum possible incidence with a certain probability, such as the $90 \%$ probability that brown rot blossom blight could not exceed $20 \%$ incidence. Stochastic simulations $(8,22)$ focus on random processes in nature, 
take into account the range of all possible changes in system's outputs, and estimate the probability at certain levels of such outputs. When the range of possible changes in each component of the system is known, various stochastic processes could be applied to produce a distribution of system's outputs. This method has been applied to estimate the risks of multiple disease epidemics on wheat affected by weather conditions (14) and the risks of yield loss caused by rice blight (Pyricularia oryzae Cav.) associated with global climate changes (15).

It is important to determine what levels of inoculum potential associated with favorable environmental conditions could bring about a certain level of risk for blossom blight. Incidence of blossom blight can be estimated for a specific condition and compared with the condition that relates to the maximum risk, thus the concept of relative risk (RR). RR of brown rot blossom blight can be evaluated as a possible range of disease incidence. When the RR is low, chemical control can be omitted or postponed.

The objectives of this study were to (i) determine the effects of bloom stage, IC, temperature, WD, and their interactions on the development of brown rot blossom blight of prune, (ii) quantify the relationships between incidence of blossom blight and environmental factors, (iii) establish a method for risk assessment of prune blossom blight, and (iv) provide an estimation of risks of blossom blight associated with various environments as a reference of disease control.

\section{MATERIALS AND METHODS}

Inoculum preparation. An isolate of $M$. fructicola collected from a prune orchard in California and stored at the Kearney Agricultural Center, University of California, was used in this study.
A

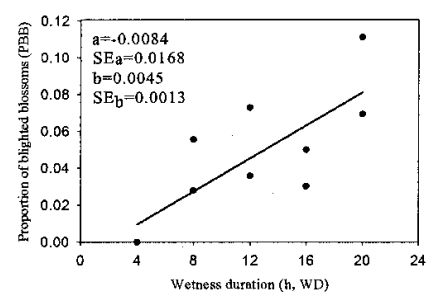

Obtain parameters from linear regressions

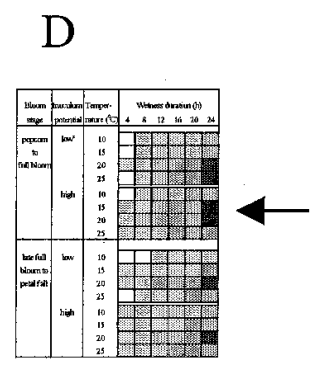

Calculate relative risk (RR) and develop a risk assessment table

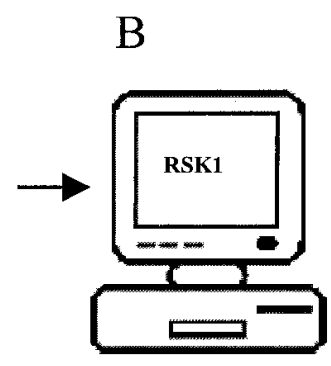

Run the program RSK1 300 times for each combination of stage, inoculum concentration and wetness duration

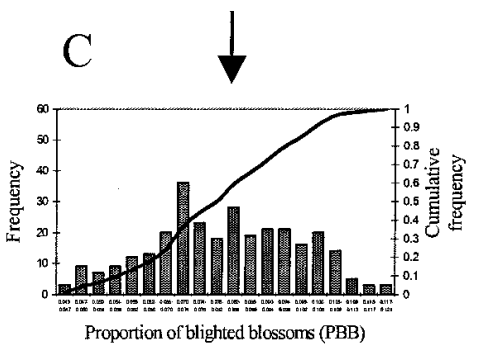

Obtain $\mathrm{PBB}_{90}$ from the frequency distribution
Fig. 1. Schematic diagram of the risk analysis for blossom blight of prune caused by Monilinia fructicola. A, The linear relationships between proportion of blighted blossoms (PBB) and wetness duration were obtained from the experiments. B, Parameters of regressions were used to run the computer program RSK1. C, The estimated distribution of PBB was obtained with stochastic simulations, and $\mathbf{D}$, information from the distributions was used to develop a risk assessment table for blossom blight.
This isolate was cultured on petri dishes containing potato dextrose agar amended with $25 \%$ ( $\mathrm{vol} / \mathrm{vol})$ lactic acid $(2.6 \mathrm{ml} / \mathrm{liter})$. The dishes were incubated at $23 \pm 2{ }^{\circ} \mathrm{C}$ for 5 days in the dark. The pathogen was subcultured under similar conditions for 5 days. Three milliliters of sterile distilled water were poured in each petri dish to harvest spores of $M$. fructicola and prepare spore suspensions for the inoculation experiments.

Experimental design. Branches were obtained from a prune (cv. French) orchard at Kearney Agricultural Center. The orchard contained 14 rows with nine trees per row. Experiments were conducted at five blossom stages (19): popcorn, full bloom, late full bloom, petal fall, and fruit set. Experiments were started 19 March and ended 15 April 1999 with an interval of 4 to 5 days for each bloom stage. Branches showing uniform blossoms at each stage were selected. Branches of approximately $40 \mathrm{~cm}$ in length with 30 to 40 buds or flowers were cut arbitrarily from trees. Four branches were placed in a 16-oz plastic cup (height $\times$ top diameter $=$ $12 \times 10 \mathrm{~cm}$ ) and inoculated with $30 \mathrm{ml}$ of a spore suspension of 10,000 conidia of $M$. fructicola per milliliter by uniformly spraying each branch with a hand-held sprayer (ACE Hardware Corp., Oak Brook, IL). To keep high humidity, cups were filled with water half way, and the inoculated branches were covered with a plastic bag $(45 \times 22 \times 12 \mathrm{~cm})$ that was attached to the top of the cup with a rubber band. Two replicated cups (eight branches total) were placed in an incubator at each of seven temperatures, $5,10,15,20,25,30$, and $35^{\circ} \mathrm{C}$, for $24 \mathrm{~h}$. All the cups were removed from the incubators and placed at room temperature $(23 \pm$ $2^{\circ} \mathrm{C}$ ) for 2 days, then in a storage room at $4^{\circ} \mathrm{C}$ for 3 days to promote sporulation. The plastic bag was removed and numbers of total and blighted blossoms showing sporulation of M. fructicola on flower calyx and stem were determined for each branch. The inoculation at popcorn stage was conducted once, whereas each of the inoculations at the other bloom stages were repeated the next day following the first inoculation on a new set of flowers. A randomized complete block design (7) was applied in 1999. Temperature was treated as main factor and bloom stage as a block. Each cup was treated as a replicate, and two replicates (cups) were used for each treatment of temperature at each blossom stage.

In 2000, inoculations were conducted at five blossom stages: late popcorn, late full bloom, petal fall, late petal fall, and fruit set. Experiments were started 16 March and ended 12 April with an interval of 4 to 5 days for each blossom stage. Branches were obtained from the same orchard and inoculated according to the same method used in 1999. Three ICs, 1,000, 5,000, and 10,000 conidia per $\mathrm{ml}$ of $M$. fructicola, were used. The cups with inoculated branches (four branches per cup) were placed in incubators at 10 , $15,20,25$, and $30^{\circ} \mathrm{C}$. After incubation at the respective temperature, two cups were removed from each incubator at different times, and the plastic bags were removed immediately from the cups to create $4,8,12,16,20$, and 24 -h wetness, respectively. Therefore, two cups, i.e., two replicates, were used for each treatment of IC-temperature-WD for each blossom stage. The cups with inoculated branches were placed at room temperature $(23 \pm$ $2^{\circ} \mathrm{C}$ ) for $36 \mathrm{~h}$. Each cup was placed in a moist chamber at room temperature $\left(23 \pm 2^{\circ} \mathrm{C}\right)$ for 2 days and in a storage room at $4^{\circ} \mathrm{C}$ for 2 days more. Total and blighted blossoms showing sporulation on their calyx and stem were counted for each branch.

TABLE 1. Results of analysis of variance for the 1999 experiments on the development of brown rot blossom blight of prune caused by Monilinia fructicola

\begin{tabular}{lrccc}
\hline Source $^{\mathrm{a}}$ & $\mathrm{df}$ & Mean square & $F$ value & $P>F$ \\
\hline Stage (block) & 4 & 1.1873 & 4.86 & 0.0051 \\
Temperature & 6 & 1.0926 & 4.48 & 0.0035 \\
Stage $\times$ temperature (error) & 24 & 0.2441 & $\ldots$ & $\ldots$ \\
\hline
\end{tabular}

${ }^{a}$ Prune branches at different bloom stages were inoculated with $M$. fructicola and incubated at seven temperatures. 
Data analysis. Proportions of blighted blossoms (PBB) were transformed by arcsine transformation (7) before analysis. For experiments in 1999, temperature was treated as a factor and bloom stage was used as block (7). Analysis of variances was applied to determine the significance of variances from bloom stage and temperature according to the general linear models (GLM) procedure (version 7.2, SAS Institute, Cary, NC). For experiments in 2000, a split-split-plot design (7) was used. Temperature was treated as the main-plot factor, IC as the subplot factor, and WD as the sub-subplot factor (7). Bloom stage was treated as a block. Because a few blossoms showed sporulation for most treatments in the last two bloom stages, data of these two stages were not included in the analysis. The GLM procedure was applied to determine the significance of variances from all plot factors and possible interactions. Comparisons of PBB among bloom stages and IC were performed based on the corresponding error terms (7) using DUNCAN comparison procedure. Regressions were applied to analyze the quantitative relationships between PBB and temperature and WD (SigmaPlot, version 5.0, SPSS Inc., Richmond, CA). Separate linear and nonlinear regressions were applied for all interactions showing significance to determine the quantitative relationships between PBB and the factors of the interaction. A Gaussian function was used to describe the relationship between $\mathrm{PBB}$ and temperature as follows: $\mathrm{PBB}=X_{0} \times \exp \left\{[-0.5(T-A) / B]^{2}\right\}$, in which $X_{0}$ is a parameter that determines the maximum PBB at the peak of curve, $T$ is temperature in degrees Celsius, $A$ is the corresponding $T$ value at $X_{0}$, and $B$ is a parameter that determines the shape of the curve.

Risk analysis approach. Risk analysis of blossom blight was performed with 2 years of experimental results. Because 24-h WD and 10,000 spores per ml of IC were used in the 1999 experiments, the data were used to estimate the risk of blossom blight at different bloom stages and temperatures under such favorable conditions of wetness and inoculum potential. The results of the 2000 experiments were used in risk analysis of blossom blight under various conditions of bloom stage, temperature, WD, and IC. The RR of blossom blight was calculated by the following formula: $\mathrm{RR}=\mathrm{PBB}_{g} / \mathrm{PBB}_{\max }$, in which $\mathrm{PBB}_{g}$ is the proportion of blighted blossoms at a given bloom stage or a given temperature, and $\mathrm{PBB}_{\max }$ is the maximum value of the $\mathrm{PBB}$ from all bloom stages and all temperatures. RRs of blossom blight for different bloom stages and temperatures under favorable wetness and inoculum potential conditions were obtained to produce the risk curves using the experimental data of 1999.

Several steps were involved in the risk analysis of blossom blight under various conditions using the experimental data in

TABLE 2. Results of analysis of variance for the 2000 experiments on the development of brown rot blossom blight of prune caused by Monilinia fructicola

\begin{tabular}{lrccc}
\hline Source $^{\mathrm{a}}$ & df & $\begin{array}{c}\text { Mean } \\
\text { square }\end{array}$ & $F$ value & $P>F$ \\
\hline Stage (block) & 2 & 0.1181 & 7.55 & 0.0006 \\
Temperature (main plot) & 4 & 0.2122 & 5.69 & 0.0181 \\
Stage $\times$ temperature (error of main plot) & 8 & 0.0372 & $\ldots$ & $\ldots$ \\
IC $($ subplot) & 2 & 0.2553 & 24.41 & $<0.0001$ \\
IC $\times$ temperature & 8 & 0.0096 & 0.92 & 0.5203 \\
Stage $\times$ IC (temperature) (error of & 20 & 0.0104 & $\ldots$ & $\ldots$ \\
$\quad$ subplot) & & & & \\
WD (sub-subplot) & 5 & 0.2610 & 16.10 & $<0.0001$ \\
Temperature $\times$ WD & 20 & 0.0434 & 2.68 & 0.0004 \\
IC $\times$ WD & 10 & 0.0139 & 0.86 & 0.5744 \\
IC $\times$ temperature $\times$ WD & 40 & 0.0133 & 0.82 & 0.7633 \\
Stage $\times$ WD $($ IC $\times$ temperature) (error of & 150 & 0.0162 & $\ldots$ & $\ldots$ \\
$\quad$ sub-subplot) & & & & \\
\hline
\end{tabular}

a Three bloom stages (late popcorn, late full bloom, and petal fall) stages; five temperatures $\left(5,10,15,20\right.$, and $\left.25^{\circ} \mathrm{C}\right)$; three inoculum concentrations (IC) $(1,000,5,000$, and 10,000 conidia per $\mathrm{ml})$; and six wetness durations (WD) $(4,8,12,16,20$, and $24 \mathrm{~h})$ were used.
2000 (Fig. 1). After comparing the PBB among the various bloom stages and ICs, treatments that showed no significance were combined. Linear regression of PBB on WD for each combination of bloom stage, IC, and temperature was obtained after plotting the data, which showed clear linear relationships and statistically significant differences. Parameters of the linear regressions included intercept, slope, and their standard errors (SE) (Fig. 1A). These parameters were used in the risk analysis using a method of stochastic simulation (8). A computer program RSK1 was developed with the Turbo C++ compiler (Borland Software Corporation, Scotts Valley, CA). This program requires that the user input parameters of a linear regression including intercept, slope, and their corresponding SE (Fig. 1B). RSK1 produces random numbers ranging from -1.0 to 1.0. In each computation using a regression, these random numbers were used to modify the linear regression as follows: $\mathrm{PBB}=\left(a+\mathrm{SE}_{a} \times \mathrm{RND}_{a}\right)+\left(b+\mathrm{SE}_{b} \times\right.$ $\left.\mathrm{RND}_{b}\right) \times \mathrm{WD}$, in which $\mathrm{PBB}$ is the proportion of blighted blossoms, $a$ is intercept, and $b$ is the slope of a linear regression. $\mathrm{SE}_{a}$ and $\mathrm{SE}_{b}$ are standard errors for $a$ and $b$, respectively. $\mathrm{RND}_{a}$ and $\mathrm{RND}_{b}$ are random numbers produced in RSK1 to modify $\mathrm{SE}_{a}$ and $\mathrm{SE}_{b}$, respectively. WD is wetness duration in hours. The user can enter any number of computations, requiring RSK1 to produce the corresponding number of PBB. RSK1 produces a frequency distribution of $\mathrm{PBB}$ and classifies these values of PBB into 30 groups based on the range of $\mathrm{PBB}$. The cumulative frequencies of $\mathrm{PBB}$ are calculated from the distribution of PBB (Fig. 1C). $\mathrm{PBB}_{90}$ was designated the $\mathrm{PBB}$ in which the corresponding cumulative frequency was 0.90 . The user can use RSK1 to produce $\mathrm{PBB}_{90}$ for any given WD from 1 to $24 \mathrm{~h}$. $\mathrm{PBB}_{90}$ for all conditions were used to develop a table of risk assessment for blossom blight (Fig. 1D).

In this study, 16 linear regressions were produced for 16 corresponding combinations of bloom stage, inoculum potential, and temperature. The analysis considered risk for blossom blight for

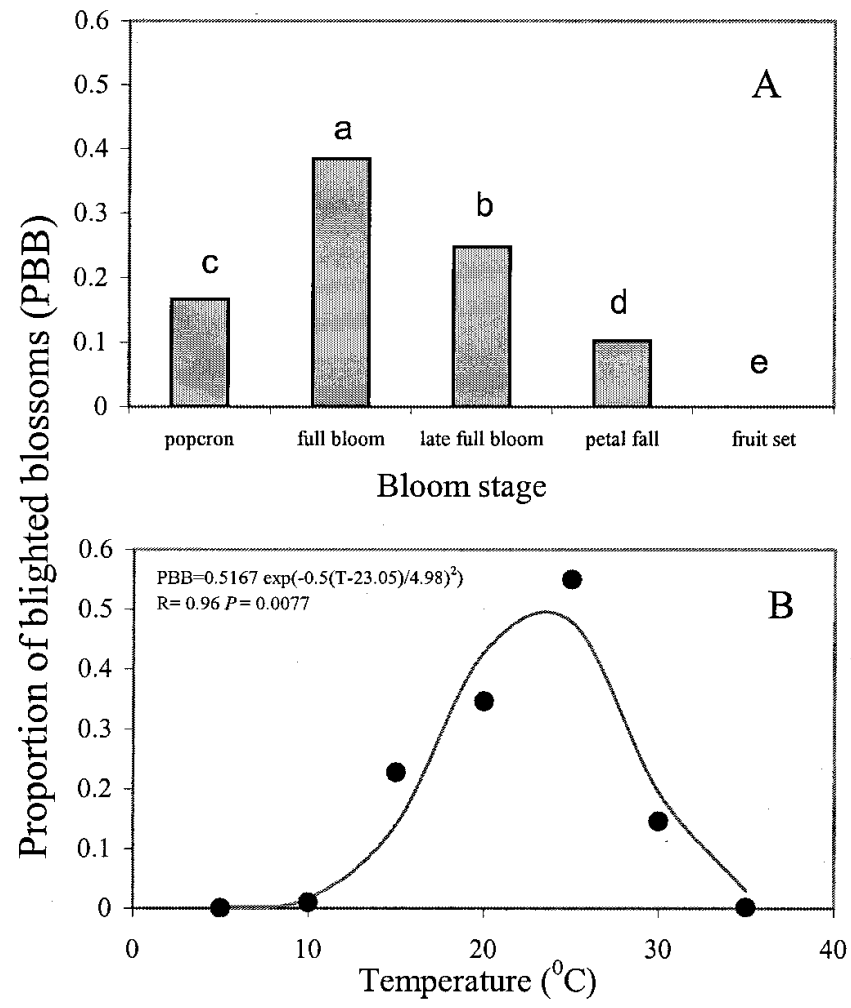

Fig. 2. A, Comparisons in proportion of blighted blossoms (PBB) of prune by Monilinia fructicola among five bloom stages, and $\mathbf{B}$, quantitative relationship between PBB and temperature $(T)$ described with a Gaussian regression. Data were from the 1999 experiments. A, Each bar is the mean of PBB from seven temperatures. B, Each data point is the mean of PBB from five bloom stages. 


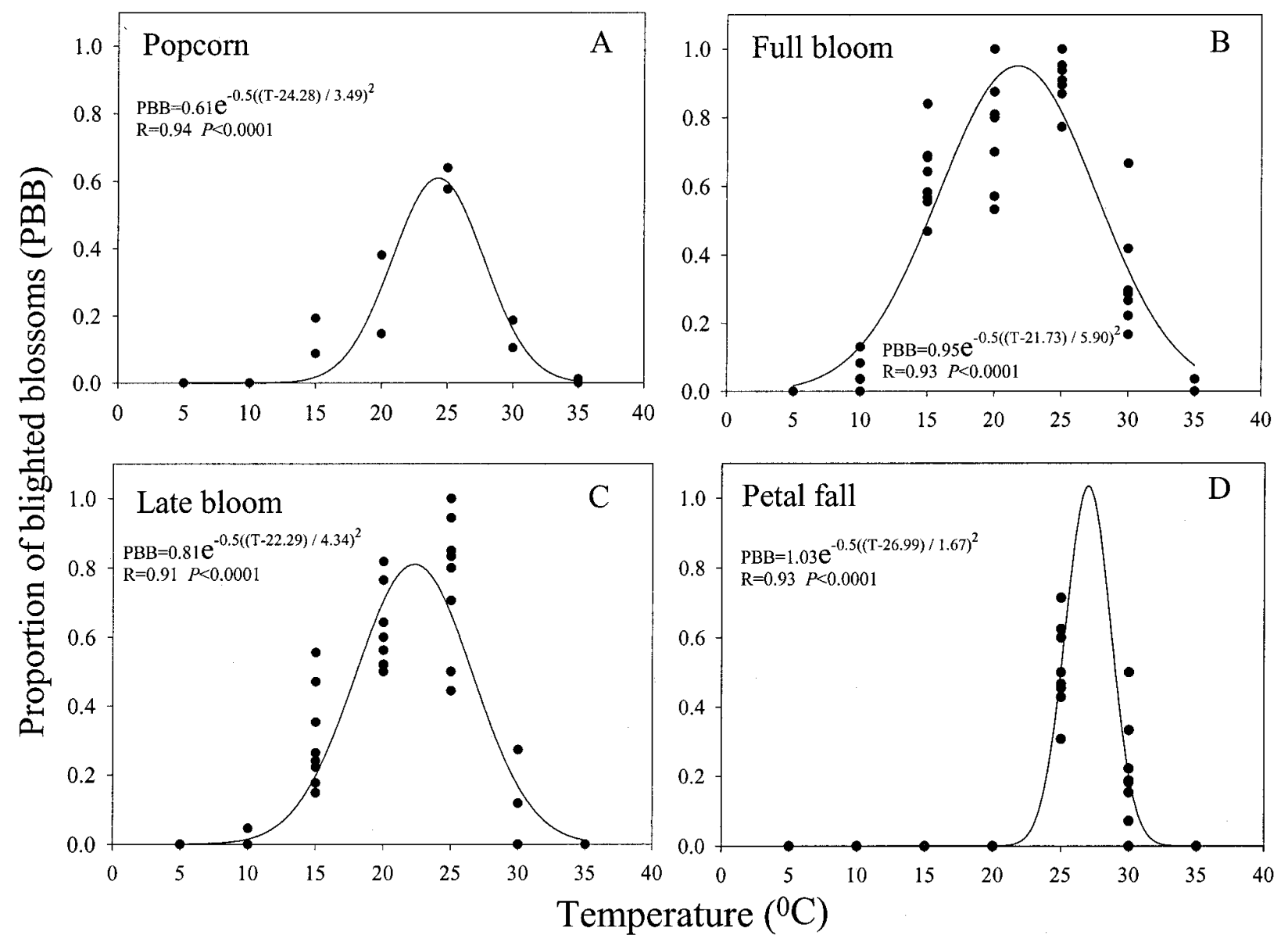

Fig. 3. Gaussian regressions between proportion of blighted blossoms (PBB) of prune caused by Monilinia fructicola and temperature (T) for four prune blossom stages. Data were from the 1999 experiments.
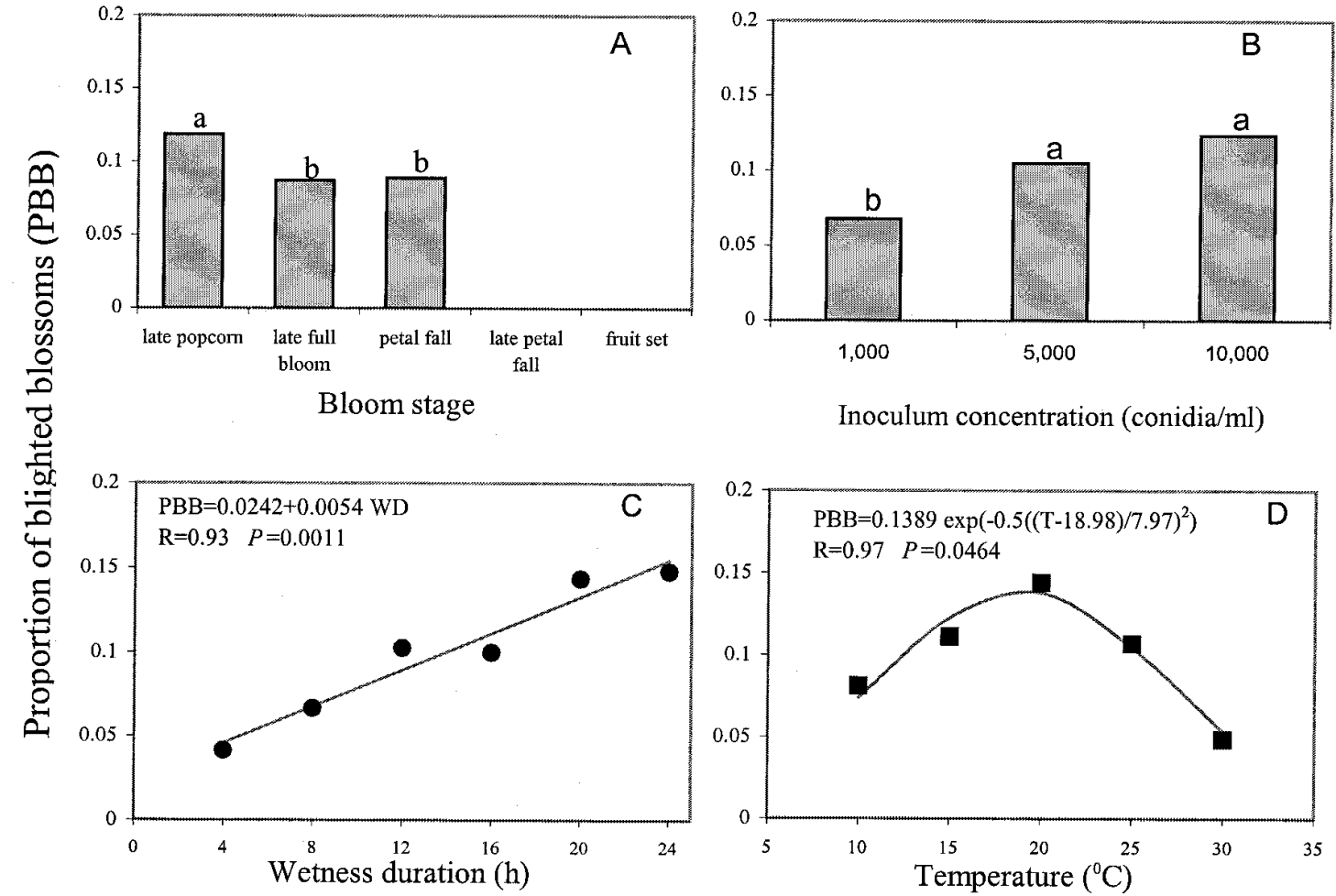

Fig. 4. Comparisons in proportion of blighted blossoms (PBB) of prune caused by Monilinia fructicola $\mathbf{A}$, among bloom stages and $\mathbf{B}$, among inoculum concentrations. C, The relationship between PBB and wetness duration (WD) is described with a linear equation, and $\mathbf{D}$, the relationship between PBB and temperature is described with a Gaussian equation. Data were from the 2000 experiments. 
two bloom stages (from popcorn to full bloom and from late full bloom to petal fall), two inoculum potentials (high $=5,000$ to 10,000 spores per $\mathrm{ml}$ and low $=1,000$ spores per $\mathrm{ml}$ ), and four temperatures $\left(10,15,20\right.$, and $\left.25^{\circ} \mathrm{C}\right)$. Under each of these combined conditions, 300 runs were performed by RSK1 for each of the six periods of WD, including 4, 8, 12, 16, 20, and $24 \mathrm{~h}$. $\mathrm{A} \mathrm{PBB}_{90}$ was produced for each WD. RR of blossom blight under a given condition of combined bloom stage, inoculum potential, temperature, and WD was calculated as $\mathrm{RR}=\mathrm{PBB}_{90 \mathrm{~g}} / \mathrm{PBB}_{90 \text { max }}$, in which $\mathrm{PBB}_{90 \mathrm{~g}}$ is $\mathrm{PBB}_{90}$ under a given condition, and $\mathrm{PBB}_{90 \text { max }}$ is the maximum $\mathrm{PBB}_{90}$ among all $\mathrm{PBB}_{90}$ from all conditions. The RRs were classified into four levels: no risk if $\mathrm{RR} \leq 0.1$, low risk when $0.1<$ $\mathrm{RR} \leq 0.4$, moderate risk when $0.4<\mathrm{RR} \leq 0.7$, and high risk when $\mathrm{RR}>0.7$. Results of the analysis were used to produce a diagram as a reference for risk assessment under different conditions.

\section{RESULTS}

There were significant differences in the PBB among bloom stages $(P=0.0051)$ and temperatures $(P=0.0035)$ (Table 1$)$ for the 1999 experiments. In the 2000 experiments, the differences in the PBB among bloom stage, temperature, IC, and WD were all significant at $P \leq 0.05$ (Table 2). The interaction of temperature and WD was significant $(P=0.0004)$ (Table 2$)$, and interactions between IC and temperature and between IC and WD, as well as the three-way interaction of the variables, were not significant (Table 2).

In 1999, the mean PBB among the five bloom stages were all significantly different $(P \leq 0.05)$ (Fig. $2 \mathrm{~A})$. The maximum PBB was observed at full bloom stage and no blighted blossoms were observed at the fruit set stage. The relationship between PBB and temperature significantly fitted a Gaussian function (Fig. 2B). The PBB was 0.52 at $23.1^{\circ} \mathrm{C}$ (peak of the curve) and 0 at both 5 and $35^{\circ} \mathrm{C}$ (Fig. 2B). Different Gaussian equations were obtained for each stage from popcorn to petal fall stage (Fig. 3). At popcorn stage, the optimum temperature for blossom blight that was related to the maximum $\mathrm{PBB}(0.63)$ was $24.3^{\circ} \mathrm{C}$ (Fig. 3A). However, a temperature range of 21.7 to $22.3^{\circ} \mathrm{C}$ at full bloom and late bloom stages related to $\mathrm{PBB}>0.6$ (Fig. $3 \mathrm{~B}$ and $\mathrm{C}$ ). The curves showed less centralized, and the peaks of the curves were wider and higher than that for the popcorn stage. At petal fall stage, most blighted blossoms were observed at 25 and $30^{\circ} \mathrm{C}$, and the curve was sharper compared with the other three curves (Fig. 3D). In summary, the temperature range leading to severe blossom blight was wider at full bloom stage than at popcorn stage, and blossoms were more susceptible to infection of $M$. fructicola at this stage than at popcorn or petal fall stages.

In the 2000 experiments, overall comparisons in mean PBB among bloom stages showed that $\mathrm{PBB}$ at late popcorn stage was significantly higher $(P \leq 0.05)$ than those at the late full bloom and petal fall stages. Very few blighted blossoms were recorded at late petal fall and fruit set stages (Fig. 4A). There were no significant differences in PBB between IC of 10,000 and 5,000 conidia per ml. However, these two ICs caused a significantly higher PBB than the concentration of 1,000 conidia per ml (Fig. 4B). PBB linearly increased with increased WD (Fig. 4C). Similar to the results of 1999 , a Gaussian equation significantly $(P=0.046)$ described the relationship between $\mathrm{PBB}$ and temperature (Fig. 4D). The peak of the curve was at approximately $19^{\circ} \mathrm{C}$ (Fig. 4D).

To determine the differences in the interaction between bloom stage and temperature, a Gaussian equation was obtained for each of the three bloom stages from late popcorn to petal fall (Fig. 5). Although all equations were significant, the curve at the petal fall stage (Fig. 5C) had a less pronounced peak than those at the late popcorn and late full bloom stages (Fig. 5A and B). The optimum temperatures for blossom blight at late popcorn and late full bloom stages ranged from 19 to $20^{\circ} \mathrm{C}$, but the optimum temperature at petal fall stage was $15.8^{\circ} \mathrm{C}$.
After combining all bloom stages, no significant correlation between PBB and temperature for the 4- and 8-h WD was determined (data not shown). Four Gaussian equations significantly $(P \leq 0.05)$ fitted the relationships between PBB and temperature for the 12-, 16-, 20-, and 24-h WD (Fig. 6). In general, although all equations were significant at $P \leq 0.05$, the $R$ values of the equations for the 12- and 16-h WD (Fig. 6A and B) were higher than those for the 20- and 24-h WD (Fig. 6C and D).

Two exponential equations described the relationship between $\mathrm{PBB}$ and $\mathrm{WD}$ at 10 and $25^{\circ} \mathrm{C}$ (Fig. 7A and D), and two linear equations described the relationships between $\mathrm{PBB}$ and $\mathrm{WD}$ at 15 and $20^{\circ} \mathrm{C}$ (Fig. 7B and C).

Under favorable conditions of 24-h WD and 10,000 conidia per $\mathrm{ml}$ of IC using the experimental results in 1999, the highest RR of blossom blight was at full bloom stage (Fig. 8A) and at 24 to $25^{\circ} \mathrm{C}$

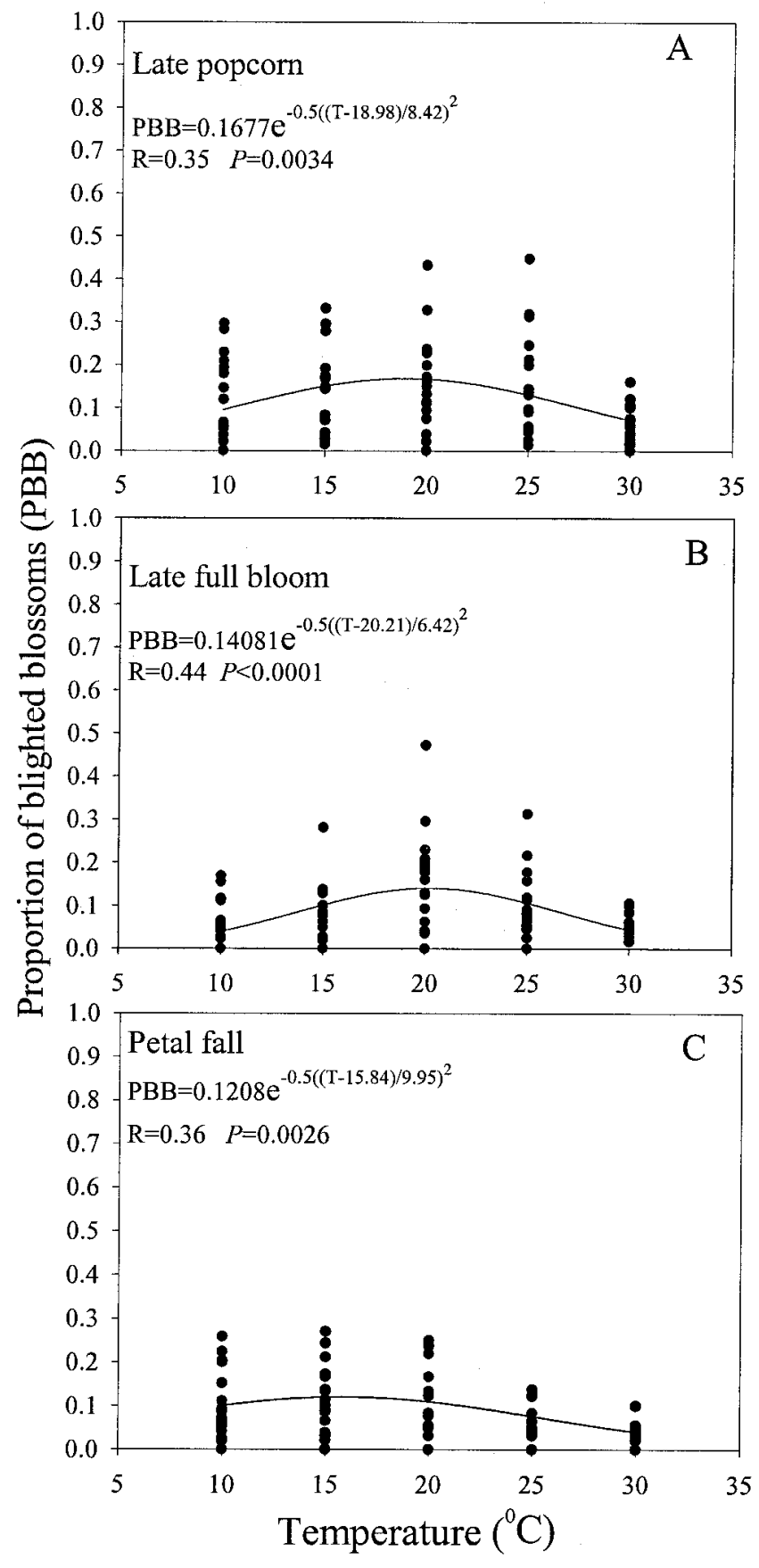

Fig. 5. Regressions of proportion of blighted blossoms (PBB) of prune caused by Monilinia fructicola on temperature $(T)$ for three bloom stages described with Gaussian equations. Data were from the 2000 experiments. 
(Fig. 8B). Using the experimental result in 2000 (10,000 conidia per $\mathrm{ml}$ at $25^{\circ} \mathrm{C}$ ), the highest RR of blossom blight was with the 24-h WD at about full bloom stage. Different WD led to different levels of RR at different bloom stages (Fig. 8C). A three-dimensional relationship among RR of blossom blight, bloom stage, and temperature was also determined (Fig. 8D).

Risk analysis used the experimental results in 2000 for two bloom stages (early popcorn to full bloom and late full bloom to petal fall), two ICs (high for 5,000 and 10,000 conidia per ml, and low for 1,000 conidia per $\mathrm{ml})$, four temperatures $(10,15,20$, and $\left.25^{\circ} \mathrm{C}\right)$, and six levels of WD $(4,8,12,16,20$, and $24 \mathrm{~h})$. Linear regressions of $\mathrm{PBB}$ on WD for each combination of bloom stage, IC, and temperature were obtained (Table 3). Although all linear equations were significant at $P \leq 0.05, R$ values varied from 0.35 to 0.78 (Table 3 ). Based on 300 runs by RSK1 and using each equation for each of the above four temperatures, the $\mathrm{PBB}_{90 \text { max }}$ was determined under the combined condition of $20^{\circ} \mathrm{C}$ with 24-h WD with high inoculum potential at early bloom stage (data not shown). The schematic diagram of RR of blossom blight (Fig. 9) based on the corresponding RR values demonstrated that there was no risk of blossom blight at early bloom stage (from popcorn to full bloom) when temperature was below $10^{\circ} \mathrm{C}$ and WD was shorter than $4 \mathrm{~h}$. When WD was $24 \mathrm{~h}$, there was a high RR of blossom blight at 20 and $25^{\circ} \mathrm{C}$ when inoculum potential was low, or at 15 and $20^{\circ} \mathrm{C}$ when inoculum potential was high (Fig. 9). Fewer cases with a high RR occur at late bloom stage (from late full bloom to petal fall) than at early bloom stage. Only the 24-h WD at $20^{\circ} \mathrm{C}$ with either low or high inoculum potential may be associated with severe blossom blight. Most conditions resulted in low to moderate risk of blossom blight. In summary, there were 22 and 28 conditions associated with low risk, and 18 and 15 conditions associated with moderate risk of blossom blight at early and late bloom stages, respectively. With low inoculum potential, there were 26 conditions associated with low risk at early bloom stage and 13 conditions associated with moderate risk of blossom blight at late bloom stage. With high inoculum potential, there were 24 conditions associated with low risk at early bloom stage and 20 conditions associated with moderate risk of blossom blight at late bloom stage.

\section{DISCUSSION}

Bloom stage, IC, temperature, and WD all influenced brown rot blossom blight of French prunes, and different combinations of these four factors were associated with different levels of disease risk. In summary, early bloom stages were associated with higher risk of blossom blight than late bloom stages. Higher IC was associated with greater incidence of blossom blight than lower IC. Temperatures from 20 to $25^{\circ} \mathrm{C}$ were optimum to the disease. WD longer than $4 \mathrm{~h}$ linearly increased the risk of blossom blight. The results of this study also implied that resistance of blossoms to infection may increase later in the bloom period. Under field conditions, the risk of blossom blight may be significantly reduced if favorable weather occurs at a late bloom stage instead of at an early bloom stage.

A similar study on phenological analysis of brown rot blossom blight of sweet cherry, caused by M. laxa, was reported by Tamm et al. (21). They investigated the influence of temperature and WD
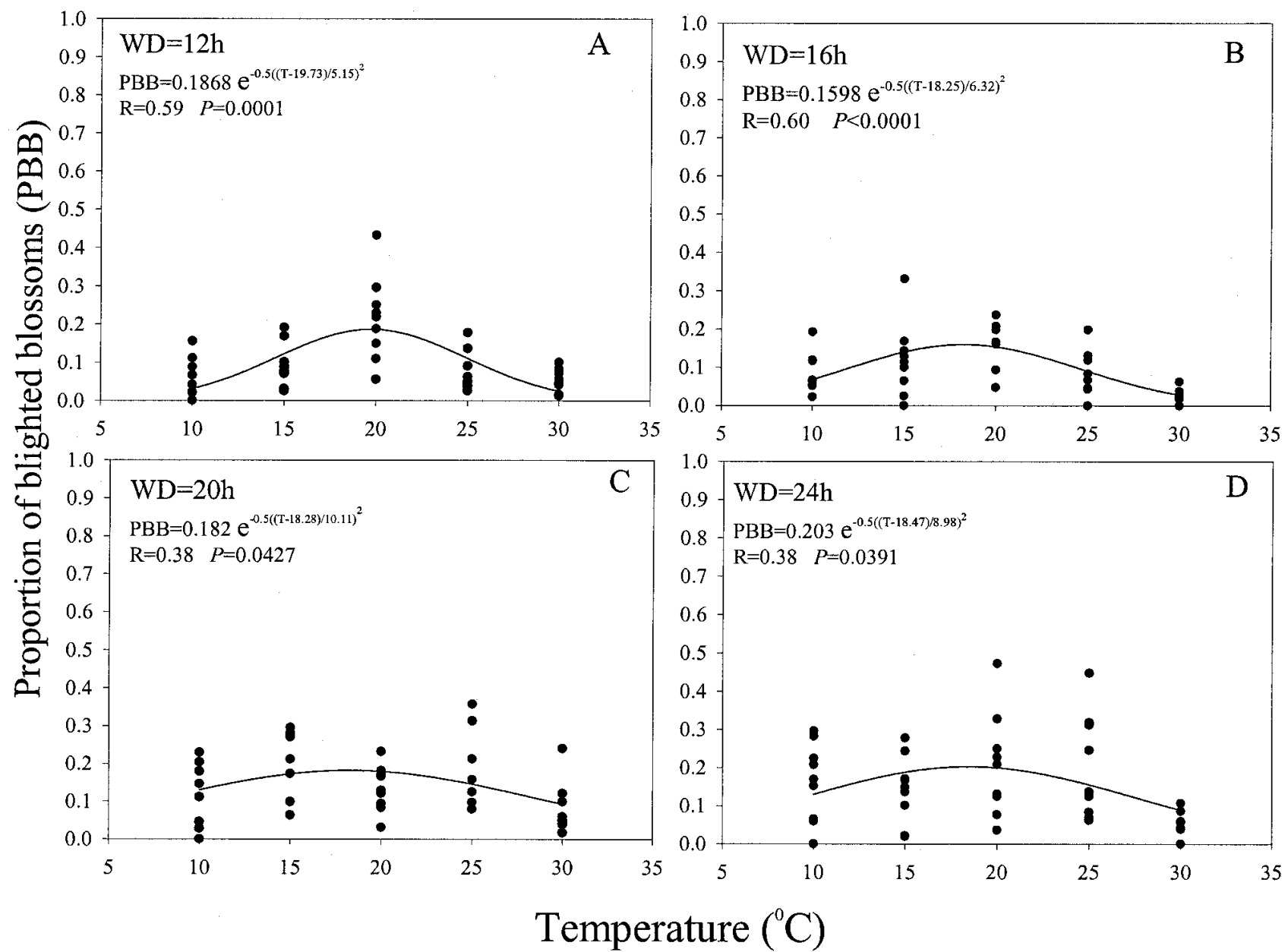

Fig. 6. Regressions of proportion of blighted blossoms (PBB) of prune caused by Monilinia fructicola on temperature (T) for different wetness durations (WD) described with Gaussian equations. Data were from experiments in 2000. Observations of each graph were from three bloom stages and three inoculum concentrations. 
on infection incidence of sweet cherry blossoms in Switzerland. They combined Richards and Analytis' beta models (21) into a nonlinear model to describe the infection incidence as a function of both temperature and WD. The model was used to predict the effect of temperature and WD on disease incidence. In general, similar trends were found at different temperatures in which proportion of infected blossoms increased with increased WD. The model was used to predict the possible range of incidence of blossom blight resulting from combinations of different temperatures and WD. Our study differs from Tamm et al. (21) in that we emphasized the effects of temperature and WD on blossom blight at different bloom stages instead of disease severity development at a single stage. Because interactions between temperature and WD were different at different bloom stages, the effects of these two factors were analyzed separately in our study.

Generally, incidence/severity of either blossom blight or fruit brown rot increased linearly $(21)$ or exponentially $(2,12)$ with increased WD and exponentially (21) or quadratically (2) with increased temperature. The effects of combination of WD and temperature on brown rot were described by sigmoid (21) and quadratic (2) functions. In this study, we found that the Gaussian function was a suitable model to describe the relationship between incidence of blossom blight and temperature when a wide range of temperatures (from 5 to $35^{\circ} \mathrm{C}$ ) was used. An advantage of using this model is that the optimum temperature for blossom blight and the corresponding blossom blight incidence can also be determined.

Development of blossom blight seems to be a complex process influenced by many factors. We assessed possible risks of blossom blight development based on four factors during the infection process. Under natural conditions, development of blossom blight depends on conditions that occur during the infection process itself and environmental conditions during the latency period. When unfavorable conditions are encountered, symptoms of blossom blight and sporulation of $M$. fructicola may not develop on blossoms. Our field observations (data not shown) showed that the presence of favorable conditions, such as high humidity and optimum temperature for a period of 2 days or longer after infection, favor development of blossom blight. Therefore, when using results of this study as a reference for risk assessment of blossom blight in prunes, it may be necessary to consider the conditions of the 2 to 3 days after infection.

It is difficult to predict disease incidence at an exact value with current techniques, however, estimating a possible range of disease intensity can be relatively easy. Different from conventional or general disease predictions, which provide only possible disease intensity at a certain time, this study introduced an approach to provide a possible range of disease intensity with a probability of occurrence of this range. This improvement will provide the decision makers with valuable information. When the possible range of disease intensity and the corresponding probability are estimated, decision making will become easier because the probability of a certain risk may also be determined. For example, in this study, if only PBB without information of probability is given for disease prediction, growers may not be able to determine how much risk or loss they may encounter if no spray is decided. Instead, Table 9 provides information containing a range of blossom blight incidence with $90 \%$ probability that the incidence could not exceed this range. When the predicted incidence and risk are still sustainable, no spray may be used based on the growers' attitude

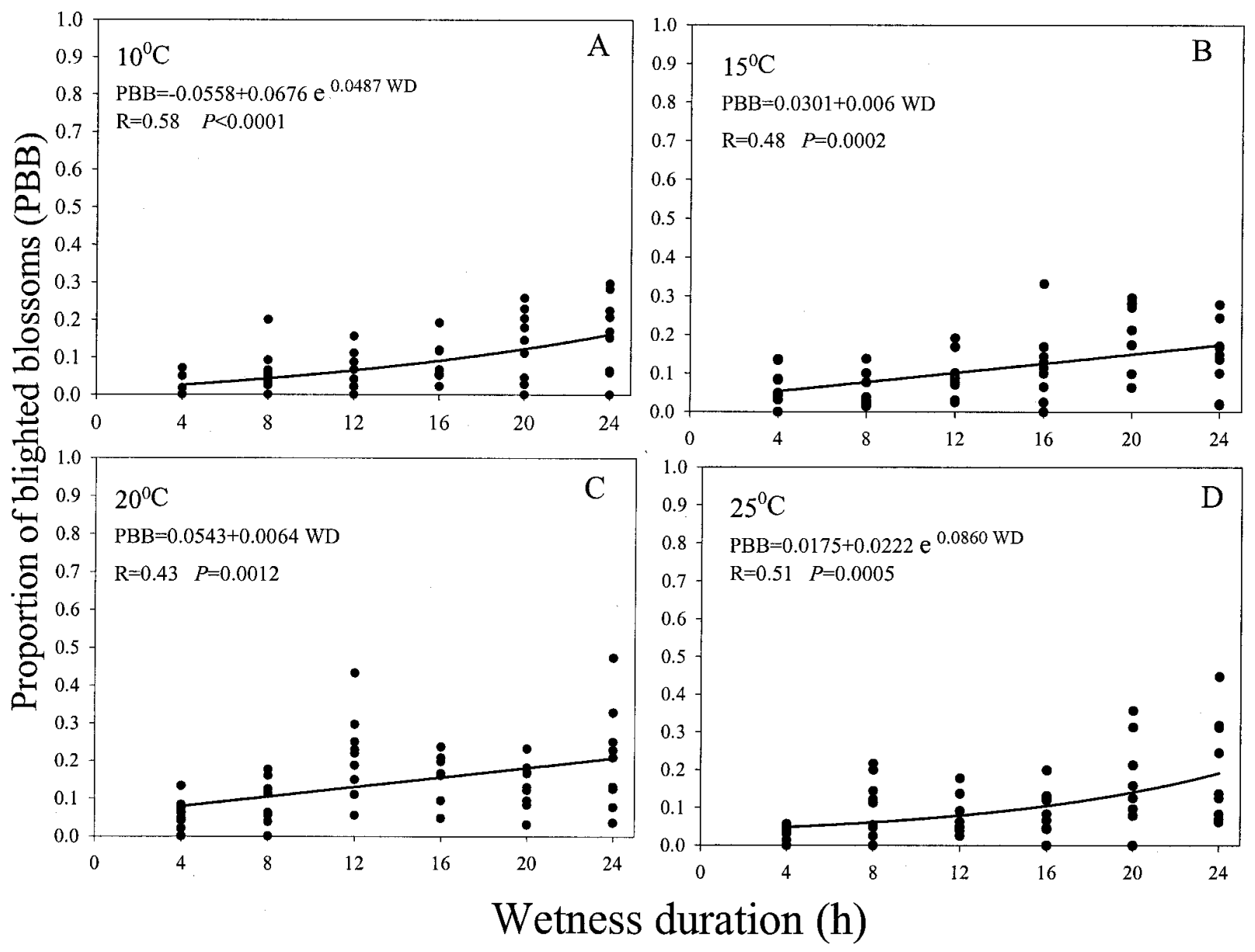

Fig. 7. Relationships between proportion of blighted blossoms (PBB) of prune caused by Monilinia fructicola and wetness durations (WD) at different temperatures. Data were from the 2000 experiments. Observations of each graph are from three bloom stages and three inoculum concentrations. 
toward risk. In fact, it is easier to decide not to spray when the predicted chance of a high risk of blossom blight is only $30 \%$, or decide to spray when the predicted chance of a high risk of blossom blight is over $90 \%$. In addition, different growers may make different decisions on whether a spray is needed when they encounter same risk level of disease intensity, especially when the chance of occurrence of threshold disease incidence for control is approximately 40 to $60 \%$. Obviously, the risk information is more advanced and useful in making a decision compared with the use of the average prediction or regression results, such as using PBB.

In this study, we used the incidence of blossom blight with $90 \%$ probability as a predicted variable for risk assessment. Decision makers may have different attitudes toward the risk. For example,
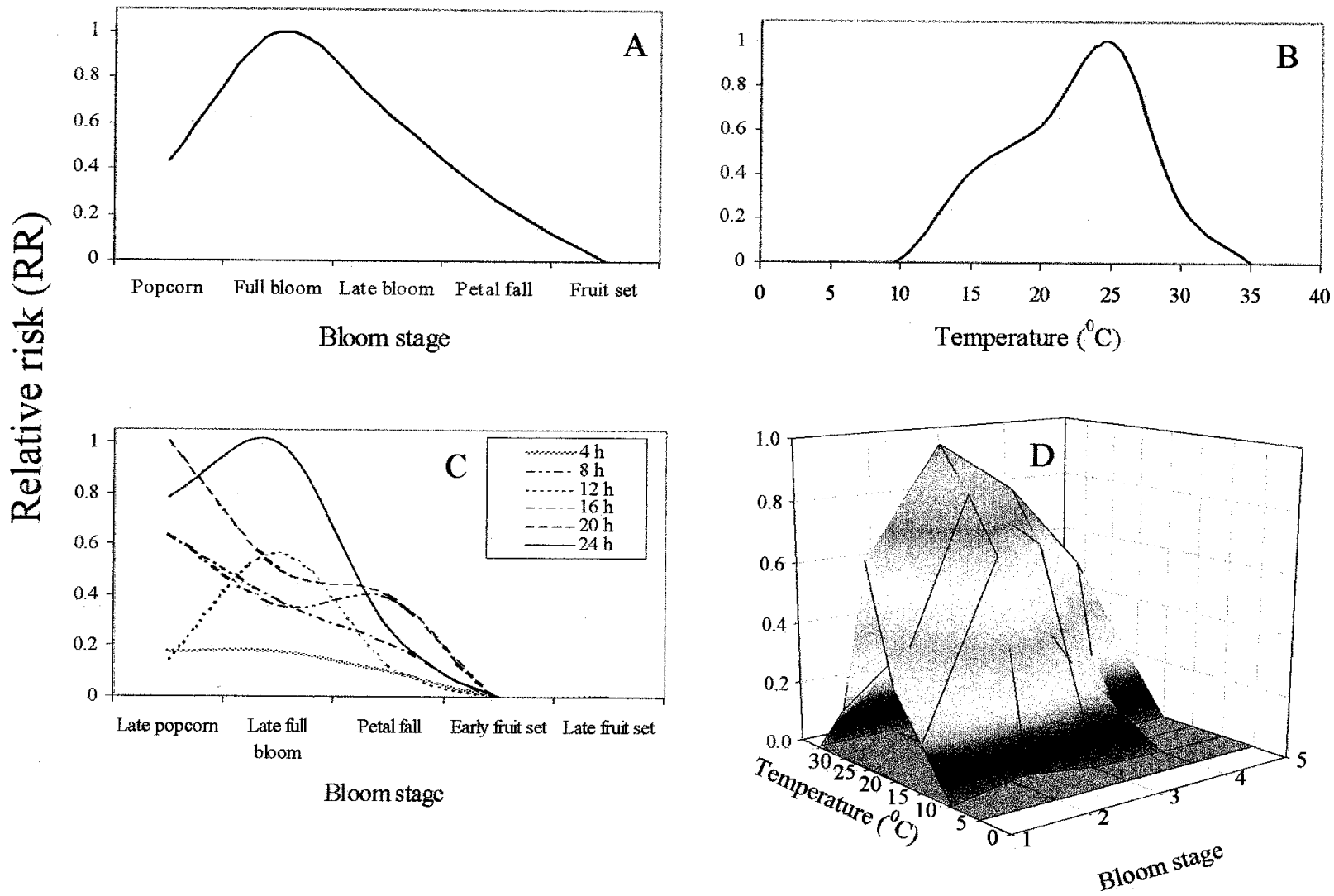

Fig. 8. Relative risk (RR) of blossom blight of prunes caused by Monilinia fructicola versus A, bloom stage and B, temperature by using 1999 experimental results, and $\mathbf{C}$, versus bloom stage for different periods of wetness durations by using 2000 experimental results. The relationships were obtained under favorable conditions for blossom blight, including 10,000 conidia per $\mathrm{ml}$ at $25^{\circ} \mathrm{C}$ for $\mathbf{A}$, full bloom stage for $\mathbf{B}$, and $25^{\circ} \mathrm{C}$ at popcorn stage for $\mathbf{C}$. D, The threedimensional graph uses the experimental results of 1999. D, The corresponding bloom stages are $1=$ popcorn, $2=$ full bloom, $3=1$ late bloom, $4=$ petal fall, and $5=$ fruit set.

TABLE 3. Parameters for linear regressions between proportion of blossom blight of prune caused by Monilinia fructicola and wetness duration in hours under different temperatures

\begin{tabular}{|c|c|c|c|c|c|c|c|c|}
\hline \multirow[b]{2}{*}{ Bloom stage } & \multirow{2}{*}{$\begin{array}{l}\text { Inoculum } \\
\text { potential }^{\mathrm{a}}\end{array}$} & \multirow[b]{2}{*}{ Temperature $\left({ }^{\circ} \mathrm{C}\right)$} & \multicolumn{6}{|c|}{ Parameters of linear regression ${ }^{b}$} \\
\hline & & & $a$ & $\mathrm{SE}_{a}$ & $\bar{b}$ & $\mathrm{SE}_{b}$ & $R$ & $P>F$ \\
\hline \multirow[t]{5}{*}{ Popcorn to full bloom } & Low & 10 & -0.0415 & 0.0317 & 0.0086 & 0.0022 & 0.6641 & 0.0008 \\
\hline & & 15 & -0.0243 & 0.0419 & 0.0089 & 0.0027 & 0.5821 & 0.0036 \\
\hline & & 25 & -0.0749 & 0.0939 & 0.0142 & 0.0063 & 0.4500 & 0.0277 \\
\hline & High & 10 & -0.0885 & 0.0341 & 0.0145 & 0.0027 & 0.7087 & $<0.0001$ \\
\hline & & 15 & -0.0131 & 0.4165 & 0.0126 & 0.0028 & 0.5715 & $<0.0001$ \\
\hline \multirow{6}{*}{ Late full bloom to petal fall } & & 15 & 0.0558 & 0.0361 & 0.0055 & 0.0024 & 0.4217 & 0.0319 \\
\hline & & 20 & -0.0161 & 0.0479 & 0.0119 & 0.0037 & 0.5436 & 0.0034 \\
\hline & & 25 & -0.0737 & 0.0375 & 0.0146 & 0.0032 & 0.7241 & 0.0002 \\
\hline & High & 10 & 0.0291 & 0.0249 & 0.0075 & 0.0016 & 0.5062 & $<0.0001$ \\
\hline & & 15 & 0.0329 & 0.0302 & 0.0076 & 0.0020 & 0.4178 & 0.0004 \\
\hline & & 20 & 0.0511 & 0.0481 & 0.0123 & 0.0033 & 0.4358 & 0.0004 \\
\hline
\end{tabular}

${ }^{\mathrm{a}}$ Low $=1,000$ conidia per $\mathrm{ml}$; and high $=5,000$ to 10,000 conidia per $\mathrm{ml}$.

${ }^{\mathrm{b}} a=$ intercept of linear regression; $\mathrm{SE}_{a}=$ standard error of the intercept; $b=$ slope of linear regression; and $\mathrm{SE}_{b}=$ standard error of the slope. Regressions were from experiments conducted in 2000. The regressions were used in risk analysis of prune blossom blight for the corresponding temperatures under different inoculum potentials and at different bloom stages. 
faced with the same risk of predicted disease, one individual may decide to spray to avoid any loss, and another may decide not to spray to sustain a certain risk of loss. The RSK1 program can also produce estimated incidence of blossom blight with 50 or $70 \%$ probability, designated $\mathrm{PBB}_{50}$ or $\mathrm{PBB}_{70}$, respectively. For an individual who is considered a decision maker and would like to be challenged with a higher risk, such as 30 or even $50 \%$ risk, these assessments could be useful in a disease management program.

Commercial recommendations to control blossom blight in California prunes dictate spray at the green tip stage. This recommendation is in agreement with the findings of this study. Fungicides applied early (at the green tip) will protect blossoms from infections at late bloom stages when the risk of brown rot is high. Based on this study, an estimation of blossom blight risk is important because chemical control of blossom blight is needed only in orchards that historically show a high inoculum potential under favorable weather conditions during bloom. Based on the results of this study, risk of blossom blight is low or moderate under most situations, and in these cases, chemical control decisions may need to involve risk assessment. This study found that if favorable conditions are met, even low inoculum potential might cause moderate to high risk of blossom blight.

Results of this study also suggest that an estimation of inoculum potential in an orchard is of major importance in disease risk assessment. Evaluation of inoculum potential in specific orchards may help in using risk assessment approaches, and recommendations for disease control in orchards with a high inoculum potential may be very different from those in orchards with low inoculum potential. Therefore, determining inoculum potential

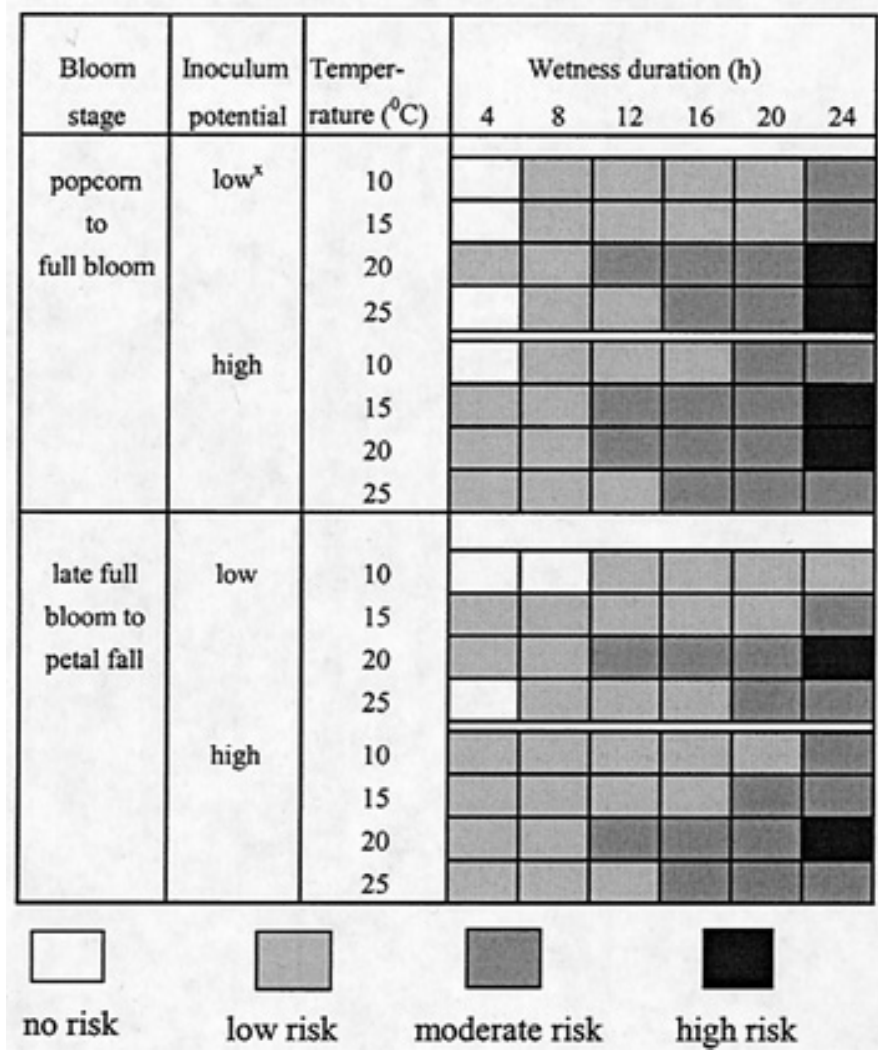

Fig. 9. Relative risks (RR) of blossom blight of prunes caused by Monilinia fructicola in relation to different bloom stages, inoculum potentials, temperatures, and wetness durations. The results were from risk analysis using stochastic simulations applied with the regression for each combination of bloom stage, inoculum concentration, and temperature (Table 3). The risks were classified into four levels (no risk, low, moderate, and high risk) according to values of RR. Low $^{x}=1,000$ spores per ml; and high $=5,000$ to 10,000 spores per $\mathrm{ml}$. in early spring may be necessary to estimate risk of blossom blight in an orchard.

Improvement of the risk assessment process, including validation of the system, may help in reducing cost of disease control and delay fungicide resistance development. The risk assessment approach is a component of a decision support system guiding control of blossom blight in prunes. Extensive studies not only involve risks of disease development, but also need to consider risks of fungicide resistance, yield losses, and economic profits. Therefore, the risk analysis approach is also a component of an integrated pest management program for control of brown rot.

\section{ACKNOWLEDGMENTS}

This research was funded by the California Prune Board. We thank D. Felts and J. Danforth for their assistance in these experiments.

\section{LITERATURE CITED}

1. Biggs, A. R., and Northover, J. 1985. Inoculum sources for Monilinia fructicola in Ontario peach orchards. Can. J. Plant Pathol. 7:302-307.

2. Biggs, A. R., and Northover, J. 1988. Influence of temperature and wetness duration on infection of peach and sweet cherry fruits by Monilinia fructicola. Phytopathology 78:1352-1356.

3. Byrde, R. J. W., and Willetts, H. J. 1977. The Brown Rot Fungi of Fruit: Their Biology and Control. Pergamon Press, Oxford.

4. Corbin, J. B. 1963. Factors determining the length of the incubation period of Monilinia fructicola (Wint.) Honey in fruits of Prunus spp. Aust. J. Agric. Res. 14:51-60.

5. Cornin, J. B., and Cruickshank, I. A. M. 1963. Environment and sporulation in phytopathogenic fungi. V. Monilinia fructicola (Wint.) Honey: Effect of water relations on regeneration of spores in vivo. Aust. J. Biol. Sci. 16:99-110.

6. Cruickshank, R. H., and Wade, G. C. 1992. The activation of latent infections of Monilinia fructicola on apricots by volatiles from the ripening fruit. J. Phytopathol. 136:107-112.

7. Gomez, K. A., and Gomez, A. A. 1984. Statistical Procedures for Agricultural Research. 2nd ed. John Wiley \& Sons, New York.

8. Hammersley, J. M., and Handscombe, D. C. 1964. Monte Carlo Methods. Methuen, London.

9. Hong, C. X., Michailides, T. J., and Holtz, B. A. 1998. Effects of wounding, inoculum density, and biological control agents on postharvest brown rot of stone fruits. Plant. Dis. 82:1210-1216.

10. Jerome, S. M. R. 1958. Brown rot of stone fruits: Latent contamination in relation to spread of the disease. J. Aust. Inst. Agric. Sci. 24:132-140.

11. Kable, P. F. 1965. Air dispersal of spores of Monilinia fructicola in peach orchards. Aust. J. Exp. Agric. Anim. Husb. 5:166-171.

12. Koball, D. C., Wilcox, W. F., and Seem, R. C. 1997. Influence of incubation-period humidity on the development of brown rot blossom blight of sour cherry. Phytopathology 87:42-49.

13. Landgraf, F. A., and Zehr, E. I. 1982. Inoculum sources for Monilinia fructicola in South Carolina peach orchards. Phytopathology 72:185190.

14. Luo, Y., Shen, Z. R., and Zeng, S. M. 1993. Risk analysis of disease epidemics on wheat by simulation studies. Agric. Syst. 43:67-89.

15. Luo, Y., Teng, P. S., Fabellar, N. G., and TeBeest, D. O. 1998. Risk analysis of yield losses caused by rice leaf blast associated with temperature change above and below for five Asian countries. Agric. Ecosyst. Environ. 68:197-205.

16. Michailides, T. J., Morgan, D. P., Felts, D., and Krueger, W. 1997. Ecology and epidemiology of prune brown rot and new control strategies. Pages 109-123 in: 1996 Prune Research Report and Index of Prune Research. California Prune Board, Pleasanton.

17. Northover, J., and Biggs, A. R. 1995. Effect of conidial concentration of Monilinia fructicola on brown rot development in detached cherries. Can. J. Plant Pathol. 17:205-214.

18. Phillips, D. J. 1984. Effect of temperature on Monilinia fructicola spores produced on fresh stone fruits. Plant Dis. 68:610-612.

19. Polito, S. V. 1981. Flower and fruit development. Pages 46-52 in: Prune Orchard Management. D. E. Ramos, ed. Univ. Calif. Div. Agric. Sci. Publ. 3269, Berkeley.

20. Sholberg, P. L., Ogawa, J. M., and Manji, B. T. 1981. Diseases of Prune blossoms, fruits, and leaves. Pages 121-125. in: Prune Orchard Management. D. E. Ramos, ed. Univ. Calif. Div. Agric. Sci. Publ. 3269, Berkeley.

21. Tamm, L., Minder, C. E., and Flückiger, W. 1995. Phenological analysis of brown rot blossom blight of sweet cherry caused by Monilinia laxa. 
Phytopathology 85:401-408.

22. Vose, D. 1996. Quantitative Risk Analysis: A Guide to Monte Carlo Simulation Modeling. Wiley-Interscience, New York.

23. Wade, G. C. 1956. Investigations on brown rot of apricots caused by Sclerotinia fructicola (Wint.) Rehm. I. The occurrence of latent infection in fruit. Aust. J. Agric. Res. 7:504-516.

24. Wade, G. C., and Cruickshank, R. H. 1992. The establishment and struc- ture of latent infections with Monilinia fructicola on apricot. J. Phytopathol. 136:95-106

25. Wilcox, W. F. 1989. Influence of environment and inoculum density on the incidence of brown rot blossom blight of sour cherry. Phytopathology 79:530-534.

26. Zehr, E. I. 1985. Importance and control of blossom blight in the southeastern United States. N. Y. State Agric. Exp. Stn. Spec. Rep. 55:2-4. 